\title{
Promoting ICT Skills through Online Services: Case Study of Video Use for Adult Education in Municipalities
}

\author{
Andreea Molnar ${ }^{1}$, Vishanth Weerakkody ${ }^{2}$, and Ahlam Almuwil ${ }^{2}$ \\ ${ }^{1}$ Arizona State University \\ andreea.molnar@asue.edu \\ ${ }^{2}$ Brunel University \\ \{vishanth.weerakkody, ahlam.almuwil\}@brunel.ac.uk
}

\begin{abstract}
The usage of video communication in public services can alleviate some of the existing problems these services face in their adoption and also help in increasing the level of outreach to citizens. In this article we focus on the usage of video-to-video (V2V) communication in municipality services for ICT education of senior citizens. For this purpose, our study focuses on determining criteria that are important for both the teachers and citizens in using such an innovative service. This paper reports on the findings from focus group consultations conducted with teachers and students, in this case senior citizens, of a municipality in Spain who was piloting the use of V2V services for adult education. The research identified several criteria relevant for consideration when deploying $\mathrm{V} 2 \mathrm{~V}$ as part of a local government service portfolio, of which, trust, quality of service and convenience emerged as common for all stakeholders involved.
\end{abstract}

Keywords: public services, adult education, video-to-video, smart cities.

\section{Introduction}

With the increased digitization of society, the usage of information and communication technology (ICT) in public services has seen a rapid increase during the last few years. Although governments have continued to push digital applications to the front line of public services, not all public services are feasible to be offered online or when offered, their adoption rate has not always been as high as expected [1, 2]. It is likely that some services have not been used due to the lack of awareness and interest on the part of citizens or those citizens were trying to use some of these online services but failed to fully complete them and ended up using other means [3]. For some other services, deeprooted issues were found such as accessibility, lack of inclusion of the elderly and the difficulty to provide the same rich interaction as they find in face-to-face services. This is particularly true when dealing with complex services such as health and education and social or domestic services such as social security, housing or employment $[4,5]$. This research focuses on education for senior citizens.

The poor adoption of eGovernment has led to public services being available both online and also mirrored via other channels [3]. However, it is not always possible to 
ensure that human resources are constantly available or that it is possible to reach people that may need a certain service, but are not located closely to the centres that offer these services. This is particularly true in the current environment, where local governments are facing growing deficits, loss in revenues and increasing costs [6] while at the same time dealing with citizens whose usage of ICT in the private sector has led to creating new expectations [3], of high quality from services available in the public sector [7].

A potential solution to these problems is the usage of high definition (HD) video technology in the provisioning of public services [8]. This can imitate the richness found in face-to-face communication while preserving the efficiency, speed and outreach of e-government services [8]. Moreover, the involvement of citizens from the beginning of a service design and diffusion and finding out what their needs are could increase the likelihood for a service to be adopted [9]. This research seeks to explore criteria for the adoption and the usage of HD V2V communication in public services, focusing on continuous education for senior citizens. To do so, we performed focus groups with the municipality staff, the senior citizens using these services and volunteers that were helping for these services to be delivered, in Spain. This empirical research was performed in the context of the LiveCity project which is funded by the European Commission's ICP programme (EU FP7 CIP grant agreement No. 297291). The remaining sections of the paper are structured as follows. The next section presents the background of technology usage in public services and focuses on $\mathrm{V} 2 \mathrm{~V}$ communication in particular. The next section briefly introduces the proposed service and how V2V will be ensured. The following section presents the study performed. We continue with conclusions and the discussion, and the paper ends with future work.

\section{Background}

The increasing availability of the Internet and the development of ICT have made electronic services an attractive solution for delivering public services. Several benefits of using ICT in public services are cited in the literature as factors driving adoption: increasing efficiency and decreasing the cost of providing services [10], availability anytime and anywhere [11], being able to provide more personalised solutions that put citizens in the center [12], and providing more transparent and accountable services [13]. It is considered that an e-government service is successful when that service is highly adopted.

The usage of HD V2V has been seen as a solution for providing personalised services and as a means to offer help for citizens that have problems using current e-government services [8]. Several preliminary studies have been performed on determining criteria for the usage of $\mathrm{V} 2 \mathrm{~V}$ in education $[14,15]$ but to the best of our knowledge they have not yet focused on local e-government services such as continuous education for senior citizens. In addition, although prior research has identified some common criteria for the usage of HD video, it is necessary to define these criteria based on the context in which the service is used [16] as prior research has shown failed attempts to measure new contexts when using general scales [17]. 
Education increases the well-being of an individual and strengthens their independence [18] and for senior citizens, it makes them live more productively and less isolated [19]. When lifelong education is offered to senior citizens, it is mostly focused on the usage of information technology [20,21]. To do so, these communities need to have some basic ICT skills. Being able to access a program that teaches basic ICT skills is significantly influenced by the access to training by senior citizens [20]. It has been shown that having computer skills can positively affect the life of citizens and improve their social relationships [22]. However the resources allocated to teach senior citizens basic information technology skills are usually limited [20]. Therefore it is necessary to find new ways to give access for more citizens to these types of services. To the best of our knowledge the study covered in this paper is the first study that attempts to use V2V technology to teach senior citizens computer skills.

\section{$3 \quad$ Research Context}

This research is done in the context of the LiveCity project. It seeks to provide HD video over public infrastructure [8]. LiveCity is user community driven and is aimed at improving core public services such as education, public administration, health and city experience in different European cities. The way LiveCity aims to ensure HD video delivery has already been discussed in our previous studies [8] and it is out of the scope of this article to examine this again. This paper focuses on education for senior citizens. The usage of V2V for these services will happen in Valladolid, Spain.

The usage of $\mathrm{V} 2 \mathrm{~V}$ for providing education for senior citizens would allow one teacher to connect to several citizens at any given time. For example, V2V will allow teaching two classes at the same time, one face-to-face and another through a video connection or having senior citizens connecting from their home. This would allow more senior citizens to benefit from lifelong learning and eliminate the need for having several teachers or facilitators, which from a municipality perspective will be one of the biggest challenges when delivering such a programme. This could also allow people that do not live in the proximity of a municipality center where these courses take place, to connect from their home. The challenge in this instance is whether the senior citizens will accept this type of technology and if they will be able to use it. This is a significant challenge as the citizens will need to make use of the ICT skills they are learning through $\mathrm{V} 2 \mathrm{~V}$ in order to receive the training. Therefore, the acceptability and the way one would design the interface to make it suitable for learners are among the challenges one faces when offering such remote training.

The service focused in this paper was originally designed by the Municipality of Valladolid as a means of helping adult citizens enhance their ICT skills. At present, volunteers teach the classes that take place in one of the venues offered by the municipality using face-to-face communication. The motivations for considering video to facilitate this service has been influenced by the fact that these classes are typically overbooked and currently there are not enough volunteers to teach them on a face-to-face basis. Due to the current economic climate there are no plans for the municipality to increase the number of classes or to hire teachers to compensate for the demand, therefore $\mathrm{V} 2 \mathrm{~V}$ 
communication is seen as an appropriate solution to increase the service offered without additional cost to the municipality. Moreover, the elderly population is increasing and the usage of ICT can allow them to live a more independent, productive and less isolated life [19]. Senior citizens, particularly those whose families live away from home, are often motivated to take these classes as they use ICT skills gained to communicate with their families.

\section{Study}

The aim of our study was to determine which criteria would be important for the adoption of $\mathrm{V} 2 \mathrm{~V}$ services, if they were offered to citizens as part of their municipality services. To achieve this aim, we focused on consulting the stakeholders using a qualitative approach. The motivation for adopting a qualitative, rather than a quantitative (such a survey) is because it allowed the researchers to get close to reality as possible and explore criteria that need to be considered from a user perspective for such a new type of service to be successful.

\subsection{Methodology}

Exploratory research was chosen due to the scarcity of empirical work related to the usage of $\mathrm{V} 2 \mathrm{~V}$ in the public sector for this particular service. Case study research is useful when dealing with broad and complex phenomenon, and the existing body of knowledge is insufficient to permit posing casual questions [23]. Due to the lack of understanding and the complexity involved in the area of research under investigation, focus groups were used as the primary data collection method. It was not necessary to design a structured agenda to ask questions in a specific order [23], but literature reviews provided the themes to be explored during the empirical work. Focus groups are useful in providing the necessary focus needed to probe a research domain that is exploratory at present [23]. As people have different views and perspective over the same things focus groups are a suitable method to understand user views [24]. Moreover, focus groups, when used in an e-government context, were found to be helpful in finding citizen's needs and expectations for new services [9]. Two focus groups were organised and recorded as this allowed for an easier analysis of the information. A thematic analysis process [25] was used for the analysis, where emerging issues were linked to the criteria identified through literature and documenting any new issues and assigning labels to these.

The participants were given an information sheet containing information about the project, what is expected from them and their rights to withdraw from the study anytime without any prior notice or explanation and/or not to respond to the questions they do not feel content in responding. Participants demographic data were collected prior to the interview through a questionnaire, however the participants did not have to disclose their demographic data if they did not want to. The focus group was facilitated by a moderator that introduced the scope of the focus group and guided the interview. 
The participants in the study were recruited by the local partners in the LiveCity project. The focus groups were held in Spanish and the results translated to English with the help of the Municipality of Valladolid.

\subsection{Participants}

We held focus groups with the teachers and the students all senior citizens who are part of the ICT education pilot. The teachers were males and over 56 years of age. A focus group was held with the students who took part in one of the classes. A total of fifteen students participated in the focus groups, $40 \%$ were males and $60 \%$ females. They were all over 56 years of age (53\% belonged to the 56-65 age group and $47 \%$ were over 65 years). Their education level varied from those who have finished primary education (47\%), to those who had postgraduate university education (7\%). Most of them reported having used an online (e-government) municipality service for less than one year $(94 \%)$ and the rest reported using it between two to five years. The teachers were volunteers and the students (senior citizens) lived in the municipality and its suburbs. All students in the ICT class were invited to participate in the focus group, no incentives were offered and all the students participated in the study.

\subsection{Results}

Considering the importance of involving relevant stakeholders in the implementation of ICT in public services [26], in this study we aim to involve the volunteer teachers and the senior students. In this respect it is important to find out what criteria is necessary for these services to be successfully adopted. We followed a qualitative approach by performing focus groups with the teachers and students. We used both an inductive and deductive approach when analysing the data. When criteria emerged it was linked with the previously found criteria from the literature. If any new criteria were found, they were added to the existing list.

Teachers. A focus group was held with teachers involved in the programme. The teachers were senior citizens who knew how to use technology, some of them being retired teachers. They mentioned as their concern problems with the technology and the fact that the citizens/students are typically beginners in using a computer and therefore distrust them, but they do not see teaching these courses as difficult or that the students have a problem in getting involved. They were keen to ensure that the $\mathrm{V} 2 \mathrm{~V}$ technology used allowed them to interact with individual students as and when they had a question or needed individual attention. The teachers highlighted the need for the V2V system to incorporate features that will allow individual students to raise their hand or alert the teacher when they needed to speak in a manner that would not be intrusive to the other participants in the class, but would allow them to listen and benefit from any questions raised by others. In addition, quality of the video and voice transmission was identified by the teachers as one of the most important criteria that they were looking for in a remote, online education programme. The teachers viewed the proposed system as different to other online and distance education programmes 
as it allows real time two way V2V making the programme as close to face-to-face as possible. Table 1 summarizes the main criteria identified by the teachers.

Table 1. Criteria for V2V based Education Services as Identified by Teachers

\begin{tabular}{|l|l|}
\hline Criteria & \multicolumn{1}{c|}{ Proposed Description } \\
\hline Trust & $\begin{array}{l}\text { Students confidence in the system, believing that the system is } \\
\text { reliable }\end{array}$ \\
\hline Access and Availability & $\begin{array}{l}\text { The system must be available and easily accessible by the } \\
\text { citizens/students }\end{array}$ \\
\hline Quality of Service & The system must allow high quality live video and voice \\
\hline Two way interaction & $\begin{array}{l}\text { The system has to facilitate seamless two way communication } \\
\text { between teacher and student }\end{array}$ \\
\hline Ease of use and presence & $\begin{array}{l}\text { The system should be as close to a real class room experience } \\
\text { for the teachers and students }\end{array}$ \\
\hline
\end{tabular}

Senior Citizens/Students. The focus group took place with the students of one class involved in learning computer use as part of their municipality service. A total of 15 citizens participated in the service. The students were beginners and have little or no experience in using V2V services. Trust is mentioned as one of the biggest obstacles for them in using online services as well as the fear of "doing something wrong", "breaking something". They mentioned that having the V2V connection would allow more students to be enrolled and allow other students who are on the waiting list to participate in adult education. Overall, all the students were supportive of the idea, "I like the idea". They stated that they would not mind being either in the class with the teacher or accessing the course online, as long as the teacher is interacting with them and is available "to answer questions". Some of the students suggested that video based learning will be convenient for them as they presently have to travel long distances to be physically present at the adult education class. They also thought that video based learning will be better than having to be part of a large class with others where senior citizens can easily be distracted due to the social interactions that

Table 2. Summary of Criteria for V2V services based on Citizens/Students' Views

\begin{tabular}{|l|l|}
\hline Criteria & \multicolumn{1}{|c|}{ Proposed Description } \\
\hline Trust & $\begin{array}{l}\text { Confidence in the system, believing that the system is reliable } \\
\text { and secure }\end{array}$ \\
\hline Confidence & Students belief that they could use the system \\
\hline Number of courses & $\begin{array}{l}\text { Number of courses available through the V2V service should } \\
\text { exceed those currently offered using classroom based teaching }\end{array}$ \\
\hline $\begin{array}{l}\text { Individual feel of the } \\
\text { system }\end{array}$ & $\begin{array}{l}\text { The system should allow individual interaction irrespective of } \\
\text { the number of students that are taught through the V2V service }\end{array}$ \\
\hline Convenience & $\begin{array}{l}\text { The video based learning should be convenient for those find- } \\
\text { ing it difficult to travel to a physical class room due to distance }\end{array}$ \\
\hline Ease of use & $\begin{array}{l}\text { The system should be easy to use and should feature live video } \\
\text { of both the teacher and his/her computer/keyboard when } \\
\text { needed }\end{array}$ \\
\hline Cost & $\begin{array}{l}\text { Should be cost effective for citizens when comparing internet } \\
\text { usage against travel expenses incurred to attend a physical class }\end{array}$ \\
\hline
\end{tabular}


occur in the classroom. In terms of the 'look and feel' of video based learning, the students suggested that the system should have the option where they could switch or split the screen when needed between seeing the live video of their teacher and the specific actions that need to be carried out involving the keyboard to complete an ICT function. In general, the students' needs and expectations mirrored those of the teachers as they were keen to see a system that was as close to a real classroom experience as it can be. Table 2 outlines the main criteria discussed during the focus groups.

\section{$5 \quad$ Discussion and Conclusion}

\section{$5.1 \quad$ Summary}

This paper presents a possible usage of video in public services, focusing on lifelong learning education for senior citizens. Focus groups were performed with volunteer teachers and senior citizens taking part in an education program offered by the municipality. The results show that all participants are positive about the introduction of $\mathrm{V} 2 \mathrm{~V}$ services in their municipality. The usage of $\mathrm{V} 2 \mathrm{~V}$ was seen as a way to allow more citizens to participate in education activities. Fig. 1 summarises the criteria important both from the teachers and students point of view. Trust in technology is common to both groups, whereas the rest of the criteria are group specific.

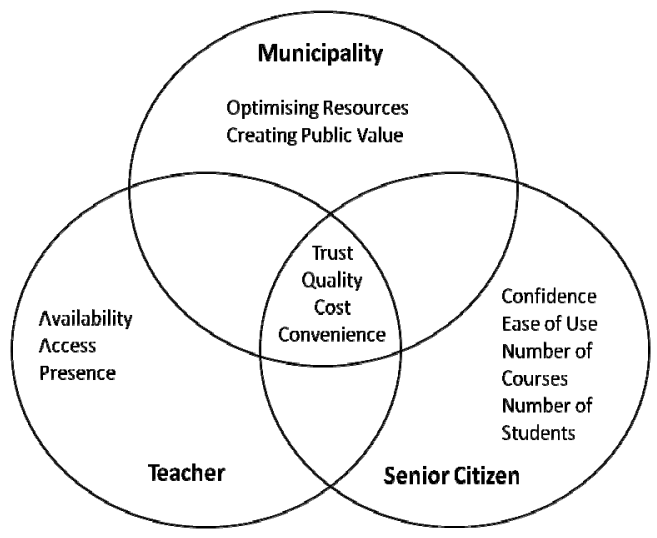

Fig. 1. Citizens generated Criteria for using V2V Communication for Adult Education

\subsection{Discussion}

Although from a supplier's perspective, the usage of ICT in public services is seen as a tool for automating and streamlining service delivery [27], in the example studied in this paper ICT is seen as a means to reach out and provide access to services to as many citizens as possible. This was highlighted in the service offered to the senior citizens in the Valladolid municipality. In the context of their adult education programme, the municipality of Valladolid is expected to teach more people at the same time, hence increasing the teacher's (and the municipality's) productivity. As the 
teachers are all volunteers no direct cost saving are seen for the municipality, but the education programme offered by the volunteers is seen as a value adding service to the municipality in terms of public perception. Citizens see the usage of V2V communication in a very positive light.

Considering the dual role of public services, to increase efficiency and be useful to citizens [9], this article has been focused on the later by aiming to better understand the needs of citizens when using a new service and determine criteria to be taken into account during the implementation and deployment of such services. By consulting the stakeholders (users and voluntary teachers) during the design and delivery of V2V services, we have tried to align the needs of the municipality with citizens' needs and expectations. It is hoped that this approach will result in better acceptance of online services in general [9] and V2V in particular, as a mechanism for adult education as well as other wider municipality services.

\subsection{Theoretical and Practical Implications}

This study adds to the state of the art by determining criteria that have to be considered for the adoption of $\mathrm{V} 2 \mathrm{~V}$ communication in the public sector as a mechanism for online service delivery. In particular, it adds to the literature of public services and adult education. To the best of our knowledge this is the first study to explore criteria necessary from the citizens' perspective when using V2V for learning ICT as part of a lifelong learning program for senior citizens.

The results presented in this research can be used by policy makers and managers and municipalities providing such services to determine what criteria are seen as relevant from the citizens' perspective in order to introduce new services or to improve the already existing ones. These criteria could also be used as a means of evaluating existing services.

\section{$5.4 \quad$ Limitations}

The results of this study are based on potential criteria as determined from focus groups with teachers and students. None of them have used the V2V system before or were involved in a similar project. Although the teachers were ICT savvy and used similar V2V services (e.g. Skype), the students did not. This may have led to difficulties in expressing what they expect from such a system [28]. The students may have also overestimated their ability to use the system without having a teacher in the class given their low level of ICT skills. The study is performed in a single location in one country and therefore cultural differences may lead to different results if the study was to be performed in another location.

\section{Future Work}

The results of this study have been taken into account when the service was implemented and deployed. Currently a small pilot is taking place in Spain. The study performed here was used to inform the design of the services and the evaluation process. 
The data about citizens and the municipality experience with the service is currently being collected and will be reported. Based on these results, improvements to the two services will be made and other criteria that may be found as a result of the participants' interaction with the system will be taken on board to continuously improve the systems. We aim for the end result of this research to be a complete taxonomy of criteria that are relevant for $\mathrm{V} 2 \mathrm{~V}$ services in the public sector. The taxonomy will be evaluated in the last stages of this research when this service will be offered on a larger scale as part of the Smart City infrastructure implemented by Valladolid in Spain.

Acknowledgements. The authors acknowledge the contributions made to this article by the LiveCity consortium of partners who are funded by the European Commission, especially to National \& Kapodistrian University of Athens for helping in organising the study presented in the paper.

\section{References}

1. Cordella, A., Contini, F.: Socio Technical Regimes and e-Government Deployment: The Case of Italian Judiciary. In: European Conference on Information Systems, Paper 27 (2012)

2. Norris, D.F., Reddick, C.G.: Local e - Government in the United States: Transformation or Incremental Change? Public Administration Review 73(1), 165-175 (2013)

3. Andersen, K.N., Medaglia, R., Henriksen, H.Z.: Frequency and Costs of Communication with Citizens in Local Government. In: Andersen, K.N., Francesconi, E., Grönlund, Å., van Engers, T.M. (eds.) EGOVIS 2011. LNCS, vol. 6866, pp. 15-25. Springer, Heidelberg (2011)

4. Andreassen, H.K., Bujnowska-Fedak, M.M., Chronaki, C.E., Dumitru, R.C., Pudule, I., Santana, S., Wynn, R.: European Citizens' use of e-Health Services: A Study of Seven Countries. BMC Public Health 7(53) (2007)

5. Santana, S., Lausen, B., Bujnowska-Fedak, M., Chronaki, C., Kummervold, P.E., Rasmussen, J., Sorensen, T.: Online Communication between Doctors and Patients in Europe: Status and Perspectives. Journal of Medical Internet Research 12(2), e20 (2010)

6. Rosenbloom, J.: Government Entrepreneurs: Incentivizing Sustainable Businesses as part of Local eEconomic Development Strategies. In: Salkin, P., Hirokawa, K. (eds.) Greening Local Government, pp. 11-22 (2011)

7. Hazlett, S.A., Hill, F.: E-Government: The Realities of Using IT to Transform the Public Sector. Managing Service Quality 13(6), 445-452 (2003)

8. Weerakkody, V., Molnar, A., Irani, Z., El-Haddadeh, R.: Complementing e-Government Services Through the Use of Video: The LiveCity Project. In: E-Government Conference, pp. 124-131 (2013)

9. Axelsson, K., Melin, U.: Talking to, not about, Citizens-Experiences of Focus Groups in Public e-Service Development. In: Wimmer, M.A., Scholl, J., Grönlund, Å. (eds.) EGOV. LNCS, vol. 4656, pp. 179-190. Springer, Heidelberg (2007)

10. Affisco, J.F., Soliman, K.S.: E-Government: A Strategic Operations Management Framework for Service Delivery. Business Process Management Journal 12(1), 13-21 (2006)

11. Bekkers, V., Homburg, V.: The Myths of e-Government: Looking Beyond the Assumptions of a new and better Government. The Information Society 23(5), 373-382 (2007) 
12. Dunleavy, P., Margetts, H., Bastow, S., Tinkler, J.: New Public Management is Dead Long Live Digital Era Governance. Journal of Public Administration Research and Theory 16(3), 467-494 (2006)

13. Dwivedi, Y.K., Weerakkody, V., Janssen, M.: Moving towards Maturity: Challenges to Successful e-Government Implementation and Diffusion. ACM SIGMIS Database 42(4), 11-22 (2012)

14. Molnar, A., El-Haddadeh, R., Hackney, R.: Facilitating the Adoption of Public Services Using High Definition Video: The Case of Primary Education. In: American Conference on Information Systems, vol. 10 (2013)

15. Weerakkody, V., Molnar, A., El-Haddadeh, R.: Indicators for Measuring the Success of Video Usage in Public Services: The Case of Education. In: American Conference on Information Systems (2014)

16. Dabholkar, P.A., Thorpe, D.I., Rentz, J.O.: A Measure of Service Quality for Retail stores: Scale Development and Validation. Journal of the Academy of Marketing Science 24(1), 3-16 (1995)

17. Dagger, T.S., Sweeney, J.C., Johnson, L.W.: A Hierarchical model of Health Service Quality Scale Development and Investigation of an Integrated Model. Journal of Service Research 10(2), 123-142 (2007)

18. Bronswijk, J.V., Bouma, H., Fozard, J.L.: Technology for Quality of Life: An Enriched Taxonomy. Gerontechnology 2(2), 169-172 (2002)

19. van Dyk, T., Gelderblom, H., Renaud, K., van Biljon, J.: Mobile Phones for the Elderly: a design framework. In: International Development Informatics Association Conference, pp. 85-102 (2013)

20. Zumarova, M., Cerna, M.: Senior Citizens as a Specific non-Traditional Group of Students in a Lifelong Education. In: Global Engineering Education Conference, pp. 771-776 (2011)

21. Dianti, M., Parra, C., Casati, F., De Angelli, A.: What's Up: Fostering Intergenerational Social Interactions. In: Designing for Inter/Generational Communities, pp. 21-27 (2012)

22. Zumarova, M.: The role of ICT in the Lives of Senior Citizens. Educational Technologies, 77-82 (2010)

23. Yin, R.K.: Case Study Research: Design and Methods. Incorporated, London, UK (2003)

24. Kitzinger, J., Barbour, R.S.: Introduction: the Challenge and Promise of Focus Groups. Developing Focus Group Research:Politics, Theory and Practice, 1-20 (1999)

25. Boyatzis, R.E.: Transforming Qualitative Information: Thematic Analysis and Code Development. SAGE Publications, Thousand Oaks (1998)

26. Goel, S., Dwivedi, R., Sherry, A.: Role of Key Stakeholders in Successful e-Governance Programs: Conceptual Framework. In: American Conference on Information Systems (2012)

27. Grant, G., Chau, D.: Developing a Generic Framework for e-Government. Journal of Global Information Management 13(1), 1-30 (2005)

28. Flak, L.S., Moe, C.E., Sæb $\varnothing, \varnothing .:$ On the evolution of e-government: The user imperative. In: Traunmüller, R. (ed.) EGOV 2003. LNCS, vol. 2739, pp. 139-142. Springer, Heidelberg (2003) 